\title{
Synergistic effect of p53 on TSA-induced stanniocalcin 1 expression in human nasopharyngeal carcinoma cells, CNE2
}

\author{
L Y Ching, Bonnie H Y Yeung and Chris K C Wong
}

Department of Biology, Hong Kong Baptist University, Kowloon Tong, Hong Kong

(Correspondence should be addressed to C K C Wong; Email: ckcwong@hkbu.edu.hk)

\begin{abstract}
Human stanniocalcin 1 (STC1) has recently been identified as a putative protein factor involved in cellular apoptosis. The use of histone deacetylase inhibitor (i.e. trichostatin A (TSA)) and doxorubicin (Dox) is one of the common treatment methods to induce apoptosis in human cancer cells. A study on TSA and Dox-mediated apoptosis may shed light on the regulation and function of STC1 in cancer treatment. In this study, TSA and Dox cotreatment in human nasopharyngeal carcinoma cells (CNE2) elicited synergistic effects on STC1 gene expression and cellular apoptosis. An activation of p53 (TP53) transcriptional activity in Dox- or Dox + TSA-treated cells was revealed by the increased expression levels of p53 $\mathrm{mRNA}$ /protein as well as p53-driven luciferase activities. To elucidate the possible involvement of p53 in STC1 gene transcription, a vector expressing wild-type or dominant negative (DN) p53 was transiently transfected into the cells. Both STC1 promoter luciferase constructs and chromatin immunoprecipitation assays did not support the direct role of p53 in STC1 gene transactivation. However, the synergistic effects of $\mathrm{p} 53$ on the induction of NF- $\mathrm{KB}$ phosphorylation and the recruitment of acetylated histone H3 in STC1 promoter were observed in TSA-cotreated cells. The overexpression of exogenous STC1 sensitized apoptosis in Dox-treated cells. Taken together, this study provides data to show the cross talk of NF- $\mathrm{B}, \mathrm{p} 53$, and histone protein in the regulation of STC1 expression and function.
\end{abstract}

Journal of Molecular Endocrinology (2012) 48, 241-250

\section{Introduction}

Stanniocalcin-1 (STC1) is known to be a hypocalcemic hormone in bony fish (Gerritsen \& Wagner 2005). It is secreted from the endocrine gland, corpuscle of Stannius and acts on the target tissues to regulate whole-body $\mathrm{Ca}^{2+}$ and $\mathrm{P}_{\mathrm{i}}$ homeostasis (Wagner et al. 1993, 1998, Lu et al. 1994). The mammalian homologue of STC1 was identified almost 15 years ago; its function, however, is largely not known (Chang et al. 1995, 1996, Olsen et al. 1996). Different from piscine, mammalian STC1 is expressed in a wide variety of tissues, acting on its target cells via autocrine/paracrine pathways (Varghese et al. 1998, De Niu et al. 2000). Therefore, the site of synthesis and release as well as the mode of action of mammalian STC1 may be altered during evolution (Yeung et al. 2012). This alternation might lead to the change in the physiological functions of STC1 from the regulation of whole-body $\mathrm{Ca}^{2+} / \mathrm{P}_{\mathrm{i}}$ homeostasis in fish to signaling at cellular and tissue levels in mammals. This assumption is sensible as in mammals serum $\mathrm{Ca}^{2+} / \mathrm{P}_{\mathrm{i}}$ homeostasis is known to be regulated by parathyroid hormone, calcitonin, and 1,25-dihydroxycholecalciferol (Khanal \& Nemere 2008, Suzuki et al. 2008). Moreover, there is no solid evidence to illustrate that mammalian STC1 plays an important role in this aspect. With increasing evidence to demonstrate the local actions of STC1, the focus of STC1 research has been moved from serum $\mathrm{Ca}^{2+} / \mathrm{P}_{\mathrm{i}}$ homeostasis to cellular inflammation and carcinogenesis (Wagner et al. 1997, Madsen et al. 1998, Chang et al. 2003, Yoshiko \& Aubin 2004, Ellard et al. 2007, Re \& Cook 2010, Sheikh-Hamad 2010).

Cancer has been considered as a chronic inflammatory disease (Lopez-Novoa \& Nieto 2009, Gupta et al. 2010, Pani et al. 2010). Cancer progression is basically the consequence of interplay among genetic, epigenetic, immunological, and microenvironmental factors (Allen \& Louise Jones 2011, Schreiber et al. 2011, Shibata 2011). Human STC1 gene is mapped at the metastatic susceptibility locus, $8 \mathrm{p}$, which is known to be related to tumor progression and metastases (Chughtai et al. 1999, Macartney-Coxson et al. 2008). The identification of the long stretches of CAG repeats in the $5^{\prime}$-untranslated region infers the propensity of genetic instability and transcriptional silencing of the gene (Chang et al. 1998, Parniewski \& Staczek 2002). Our previous study has demonstrated the epigenetic regulation of $S T C 1$ gene expression in apoptotic cancer cells treated with histone deacetylase (HDAC) inhibitors (Law et al. 2008). The possible roles of STC1 in apoptosis have been reported by different 
laboratories (Zhang et al. 2000, Wu et al. 2006, Lai et al. 2007, Block et al. 2009, Nguyen et al. 2009). The transcriptional relationship between p53 (TP53) and STC1 has also been suggested (Lai et al. 2007); however, the underlying regulatory mechanism is not clear. In this study, we were interested in this regulatory relationship, aiming to decipher the involvement of the transcriptional factor $p 53$ in the regulation of STC1 expression. Using a pharmacological approach on STC1 promoter, western blot analyses, and chromatin immunoprecipitation (ChIP) assay, our data revealed for the first time that p53-activated STC1 gene expression was via the enhancement of trichostatin A (TSA)-stimulated histone acetylation and NF- $\kappa \mathrm{B}$ signaling in the human nasopharyngeal cancer cells, CNE2. Transient overexpression of exogenous STC1 augmented doxorubicin (Dox)induced cellular apoptosis.

\section{Materials and methods}

\section{Cell culture and treatments}

The human nasopharyngeal carcinoma cell line CNE2 (a kind gift from Prof Mak, Hong Kong Baptist University, Hong Kong) was cultured in RPMI-1640 (Invitrogen, Gibco) supplemented with 10\% fetal bovine serum (HyClone; Perbio, Cramlington, UK) and antibiotics $(50 \mathrm{U} / \mathrm{ml}$ penicillin and $50 \mu \mathrm{g} / \mathrm{ml}$ streptomycin; Invitrogen, Gibco) at $37{ }^{\circ} \mathrm{C}$ with $5 \% \quad \mathrm{CO}_{2}$. Before treatment or transfection, cells were seeded at $70 \%$ confluence overnight and then treated with the NF- $\mathrm{B}$ inhibitor parthenolide (PTL; Calbiochem, La Jolla, CA, USA), the HDAC inhibitors, TSA (Calbiochem), valproic acid (VPA; Sigma), or apicidin (Calbiochem), and the chemotherapy drug Dox hydrochloride (Dox; Calbiochem) for an indicated time point.

\section{Total RNA extraction and real-time PCR}

Total RNAs were extracted using TRIZOL Reagent (Gibco/BRL) according to the manufacturer's instructions. The $\mathrm{A}_{260}: \mathrm{A}_{280}$ ratio was $>1 \cdot 8$. cDNA was synthesized from $150 \mathrm{ng}$ total cellular RNA using the High Capacity RNA-to-cDNA Master Mix (Applied Biosystems, Foster City, CA, USA). Real-time PCR was conducted using the StepOne real-time PCR detection system and POWER SYBR Green PCR Master Mix (Applied Biosystems). The amplification cycles were $95^{\circ} \mathrm{C}$ for $3 \mathrm{~min}$ and 40 cycles of $95^{\circ} \mathrm{C}$ for $30 \mathrm{~s}, 56^{\circ} \mathrm{C}$ for $30 \mathrm{~s}$, and $72^{\circ} \mathrm{C}$ for $1 \mathrm{~min}$. Fluorescent signal was captured at $72{ }^{\circ} \mathrm{C}$, and the occurrence of primer dimers and secondary products was inspected using melting curve analysis. The primers were as follows: human STC1 (CACACCCACGAGCTGACTTC-forward and TCTCCCTGGTTATGCACTCTCA-reverse), p53 (CTCCTCAGCATCTTATCCGAGTG-forward and GTGGTACAGTCAGAGCCAACC-reverse), and actin (GACTACCTCATGAAGATCCTCACC-forward and TCTCCTTAATGTCACGCACGATT-reverse). Gene expression levels of $S T C 1$ and $p 53$ were calculated by the ' $\Delta \Delta C_{\mathrm{t}}$ method' in comparison to actin.

\section{Western blot analysis}

Protein lysates were harvested using a radioimmunoprecipitation assay buffer $(50 \mathrm{mM}$ Tris-HCL, $\mathrm{pH} 7 \cdot 4$, $150 \mathrm{mM} \mathrm{NaCl}, 2 \mathrm{mM}$ EDTA, $1 \%$ Nonidet P-40, and $0 \cdot 1 \%$ SDS) following centrifugation at $10000 \mathrm{~g}$ for $10 \mathrm{~min}$. Protein concentration was measured using DC Protein Assay Kit II (Bio-Rad). Eighty micrograms of protein lysates were resolved in 10\% SDS-PAGE and the protein bands were transferred onto PVDF membranes (Bio-Rad). The membrane was blocked in $5 \%$ nonfat milk/PBS for $1 \mathrm{~h}$ and then was probed with 1000 dilution of mouse antihuman p53 (Dako, Carpinteria, CA, USA) or rabbit antihuman acetylated p53 (lys382; Cell Signaling, Danvers, MA, USA), total

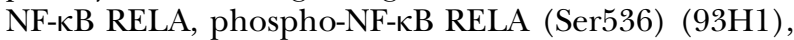
acetyl-NF- $\kappa$ B RELA (Lys310) (Cell Signaling), acetylhistone H3 (Lys9/Lys14), histone H3 (Cell Signaling), and actin serum (Sigma). Using corresponding HRPconjugated secondary antibodies (Bio-Rad Pacific Ltd.), specific bands were visualized by Western-Lightening Plus (PerkinElmer Life Sciences, Waltham, MA, USA).

\section{Transient overexpression of wild-type p53 and STC1}

pCMV-XL5 encoding wild-type $p 53$ ( $p 53 \mathrm{WT}$ ) and dominant-negative mutant $p 53$ ( $p 53$ dominant negative $(p 53 \mathrm{DN}))$ were purchased from BD Transduction Laboratories (Palo Alto, CA, USA), and pCMV-XL5 empty vector ( $\mathrm{pCMV}$ ) was obtained from Promega. For construction of STC1 overexpression plasmid, a cDNA encoding full-length human STC1 without a stop codon was ligated to an expression vector V5-tagged pLenti6.3/V5-DEST (Invitrogen). For transient transfection, $400 \mathrm{ng}$ plasmid were transfected into CNE2 cells using Lipofectamine 2000 (Invitrogen) according to the manufacturer's instructions. Overexpression efficiency was confirmed at $24 \mathrm{~h}$ of posttransfection and overexpressed cells with minimum transfection efficiency of $70 \%$ were used for assays.

\section{Annexin V assay}

After TSA and/or Dox treatment, both adherent and floating cells were collected and centrifuged at $400 \mathrm{~g}$ for $3 \mathrm{~min}$. Cell pellets were resuspended in the 
A

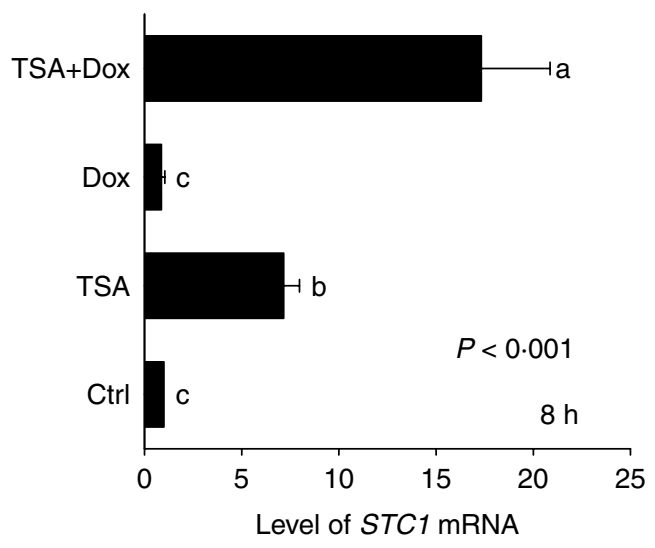

B

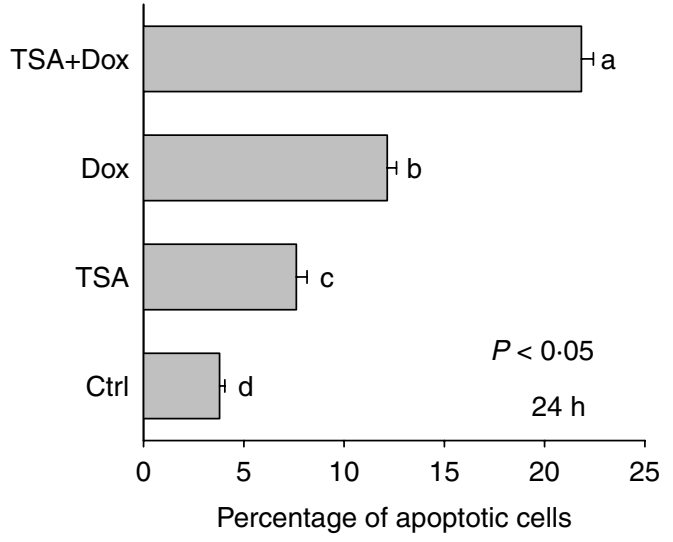

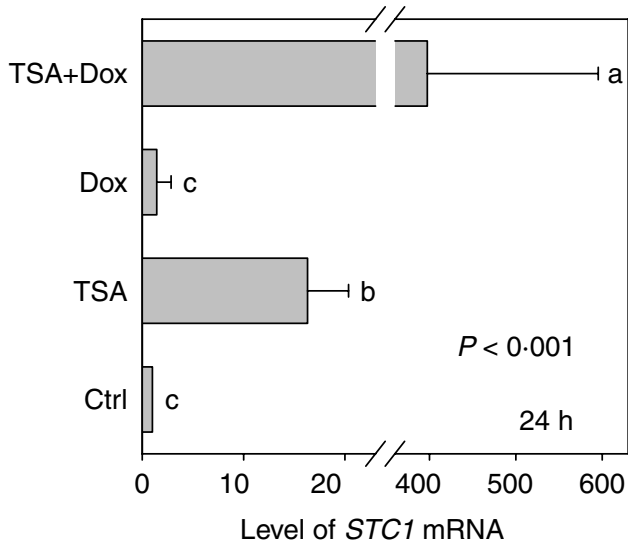

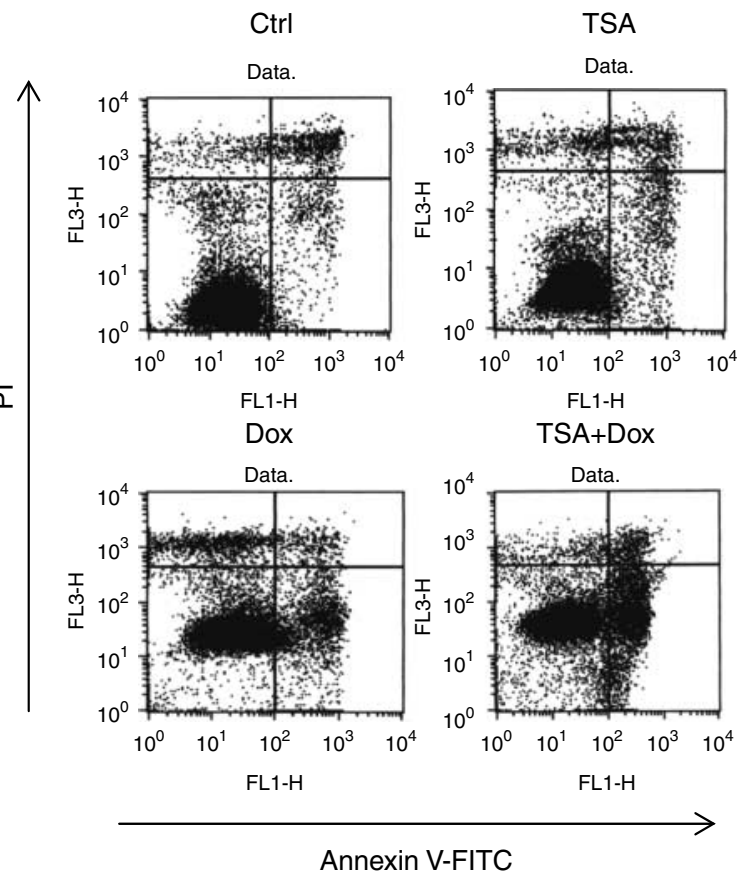

Figure 1 Effects of TSA and/or Dox treatment on STC1 mRNA expression and apoptosis in CNE2 cells. CNE2 cells were treated with TSA $(200 \mathrm{ng} / \mathrm{ml})$, Dox $(500 \mathrm{nM})$, or TSA + Dox at the indicated time points. (A) Total RNAs were harvested and subjected to real-time RT-PCR. Gene expressions of STC1 relative to actin at $8 \mathrm{~h}($ left, $P<0.001)$ and $24 \mathrm{~h}$ (right, $P<0.001$ ) are shown. (B) Treated cells were harvested at $24 \mathrm{~h}$ and stained with Annexin $\mathrm{V}$ and $\mathrm{PI}$.

Percentages of apoptotic cells (Annexin V-FITC ${ }^{+\mathrm{ve}} / \mathrm{PI}^{-\mathrm{ve}}$, the lower right quadrant in the plot) were counted using flow cytometric analysis $(P<0.05)$. Bars with the same letter are not significantly different according to the results of one-way ANOVA followed by Duncan's multiple range tests.

complete medium and then incubated in $5 \% \mathrm{CO}_{2}$ at $37^{\circ} \mathrm{C}$ for $10 \mathrm{~min}$. After centrifugation, cell pellets were washed with PBS twice and resuspended in $500 \mu \mathrm{l}$ of $1 \times$ Annexin $\mathrm{V}$ binding buffer with propidium iodide and Annexin V-FITC (BD Pharmingen, San Diego, CA, USA). The percentage of apoptotic cells was measured by flow cytometer (BD FACS Calibur).

\section{Luciferase reporter assay}

For construction of $S T C 1$ promoter luciferase reporters, different regions of human STC1 promoter $(1 \mathrm{k}:-991 /+225 ; 2 \mathrm{k}:-1842 /+225 ; 3 \mathrm{k}:-2723 /+225$; and $4 \mathrm{k}:-3867 /+225)$ were cloned into a pGL3 (SDHC) basic luciferase reporter (Promega). A pGL3 basic luciferase reporter encoding $p 53$-responsive 
promoter was purchased from Stratagene (La Jolla, CA, USA). For the assay, the reporter was cotransfected with an internal control, $p R L-S V 40$ plasmid (Promega) using Lipofectamine 2000 reagent (Invitrogen). The medium was replaced with complete medium after $6 \mathrm{~h}$ transfection and drugs were added at $24 \mathrm{~h}$ posttransfection. At the indicated time points, the cells were harvested and lysed in a $1 \times$ passive lysis buffer (Promega). The lysates were centrifuged at $10000 \mathrm{~g}$ for $2 \mathrm{~min}$, and the supernatant was subjected for luciferase activity measurement using the Dual-Luciferase reporter assay system (Promega). Firefly and renilla luciferase activities were sequentially measured for each sample by VICTOR Multilabel Reader (PerkinElmer).

\section{Chromatin immunoprecipitation}

The ChIP assay was conducted using a ChIP assay kit (Upstate, Charlottesville, VA, USA) with slight modifications. Briefly, $1 \times 10^{7}$ cells were cross-linked with $1 \%$ formaldehyde (Sigma-Aldrich) and lysed in SDS lysis buffer (1\% SDS, $10 \mathrm{mM}$ EDTA, and $50 \mathrm{mM}$ Tris-HCl, $\mathrm{pH}$ 8.0) followed by sonication to give average lengths of 200-1000 bp DNA. The sonicated chromatin was immunoprecipitated with $5 \mu \mathrm{g}$ rabbit IgG control (Sigma-Aldrich) or rabbit antihuman acetylated histone H3 (K9/K14; Upstate). DNA-protein complexes were isolated with Protein A/G Plus Agarose beads (Santa Cruz Biotechnologies, Santa Cruz, CA, USA) at room temperature for $2 \mathrm{~h}$, washed, eluted in $1 \%$ $\mathrm{SDS} / 100 \mathrm{mM} \mathrm{NaHCO}$, and cross-links reversed at $65^{\circ} \mathrm{C}$ overnight. DNA was purified using phenol:chloroform extraction, ethanol precipitation, and resuspended in $50 \mu \mathrm{l}$ water. Then, $2 \mu \mathrm{l}$ samples were subjected to realtime PCR, using the StepOne real-time PCR detection system and Power SYBR Green PCR Master Mix (Applied Biosystems). The amplification cycles were $95^{\circ} \mathrm{C}$ for $3 \mathrm{~min}$ and 40 cycles of $95^{\circ} \mathrm{C}$ for $30 \mathrm{~s}, 56^{\circ} \mathrm{C}$ for $30 \mathrm{~s}$, and $72{ }^{\circ} \mathrm{C}$ for $1 \mathrm{~min}$. Fluorescent signal was captured at $72{ }^{\circ} \mathrm{C}$, and the occurrence of primer dimers and secondary products was inspected using melting curve analysis. The primers (CACCAGACCAGTTGAGGGACCT-forward and TTTGCAAACTGGGGGCCCAAreverse) for human $S T C 1$ promoter flanking -90 to $+11 \mathrm{bp}$ at the transcription initiation site were used. The degree of enrichment in the ChIP assay was normalized with their input control.

\section{Statistical analysis}

Drug treatments were performed in triplicate at least. All data are represented as mean \pm s.D. Statistical significance was assessed using Student's $t$-test or one-way ANOVA followed by Duncan's multiple range test. Groups were considered significantly different if $P<0 \cdot 05$.
A
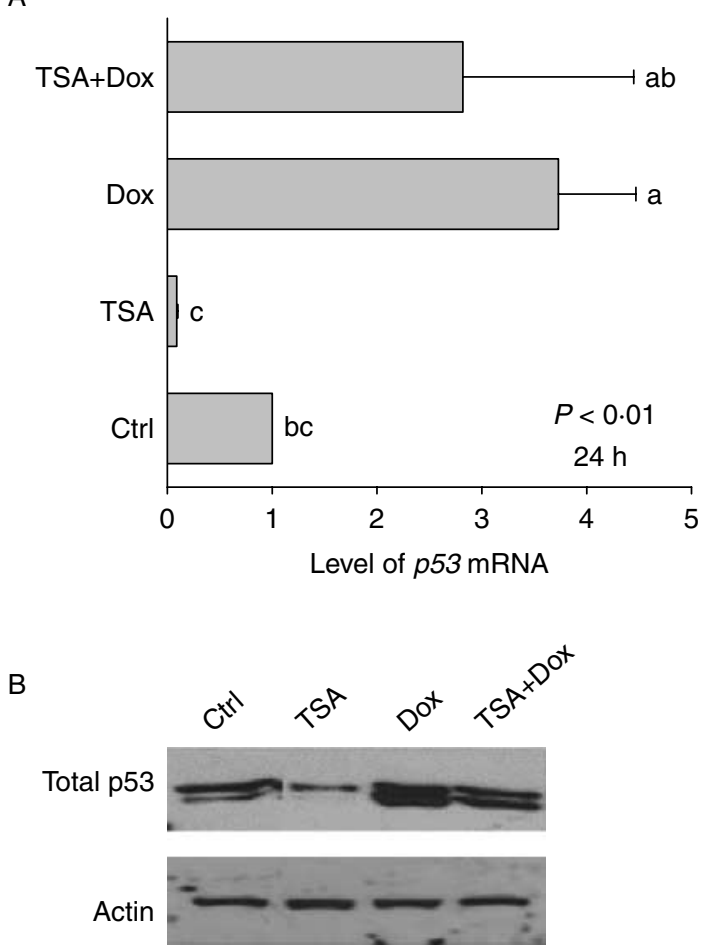

C

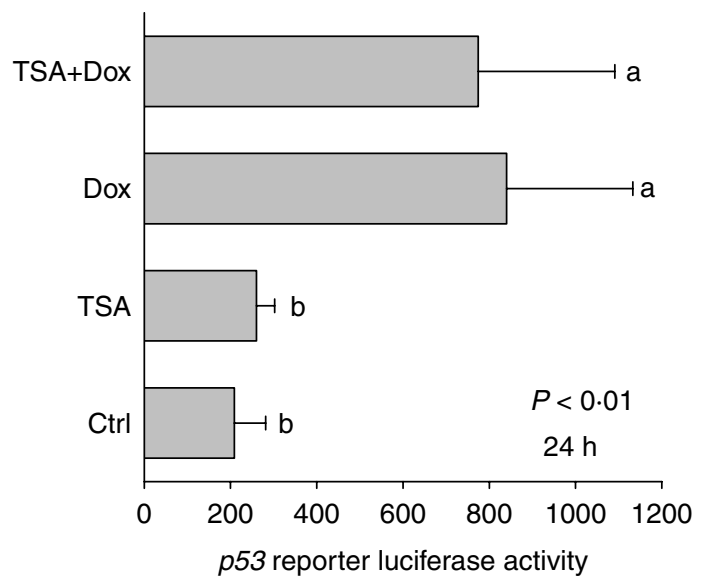

Figure 2 Effects of TSA and/or Dox treatment on p53 gene regulation. CNE2 cells were treated with TSA $(200 \mathrm{ng} / \mathrm{ml})$, Dox $(500 \mathrm{nM})$, or TSA + Dox for $24 \mathrm{~h}$. (A) Total RNAs were harvested and subjected to real-time RT-PCR. Gene expression of $p 53$ relative to actin was shown $(P<0 \cdot 01)$. (B) Protein lysates were harvested. Western blot was performed using total p53 antibody, whereas actin acted as a loading control. (C) Before treatment, CNE2 cells were transfected with $p G L 3$ plasmid containing human cloned $p 53$-responsive promoter and a normalization control plasmid $p R L-S V 40$. The cells were then exposed to TSA and/or Dox treatments for $24 \mathrm{~h}$. p53 luciferase reporter activities were measured using the dual-luciferase reporter assay system $(P<0.01)$. Bars with the same letter are not significantly different according to the results of one-way ANOVA followed by Duncan's multiple range tests. 


\section{Results}

\section{Effects of HDAC inhibitors and Dox cotreatment on the expression levels of STC1, p53, and apoptosis in CNE2 cells}

In this study, we examined the effects of HDAC inhibitors (TSA, VPA, and apicidin) and/or Dox treatment on STC1 mRNA expression in human nasopharyngeal carcinoma cells, CNE2. In $200 \mathrm{ng} / \mathrm{ml}$ TSA-treated CNE2 cells, STC1 mRNA was significantly increased by $7 \cdot 2$ - and $18 \cdot 1$-fold at both 8 and $24 \mathrm{~h}$, respectively, compared with the vehicle control (Ctrl; Fig. 1A). In $500 \mathrm{nM}$ Dox-treated cells, however, no noticeable effect on STC1 mRNA expression was observed. Interestingly, cotreatment of TSA and Dox elicited a synergistic induction of STC1 mRNA expression at both the time points $(2 \cdot 4$-fold at $8 \mathrm{~h}$ and 24-4-fold at $24 \mathrm{~h}$ vs their TSA alone treatment). Like TSA treatment, the synergistic effect was also observed in the cotreatment of Dox with the other HDAC inhibitors, $500 \mu \mathrm{M}$ VPA (5·1-fold induction vs VPA alone, Supplementary Figure 1A, see section on supplementary data given at the end of this article), or $5 \mu \mathrm{M}$ apicidin $(2 \cdot 0$-fold induction vs apicidin alone, Supplementary Figure 1B, see section on supplementary data given at the end of this article) at $24 \mathrm{~h}$. Accompanied with STC1 induction, cellular apoptosis was detected at $24 \mathrm{~h}$ treatment of either TSA $(7 \cdot 63 \%$ of apoptotic cells) or Dox (12.16\% of apoptotic cells) and was further induced in TSA+Dox cotreatment (21.83\% of apoptotic cells) compared with the control (3.79\% of apoptotic cells; Fig. 1B). In the $24 \mathrm{~h}$ treatment, mRNA expression of $p 53$ was suppressed by 6.6-fold in TSA treatment (vs Ctrl) but augmented by 3.7-fold in Dox treatment (vs Ctrl; Fig. 2A), which correlated with the total p53 protein expression level (Fig. 2B). Similar observations were observed in the treatment and cotreatment of Dox with VPA or apicidin (Supplementary Figure 2, see section on supplementary data given at the end of this article). Consistent with the expression levels, a 3.6-fold increase in p53-driven luciferase activities was measured at both Dox and TSA+Dox treatments (Fig. 2C).

\section{The association between the cellular levels of p53 and the activation of STC1 gene expression}

To elucidate the possible involvement of p53 in STC1 gene transcription, the pCMV vector expressing WT $p 53$ was transiently transfected into CNE2 cells for $24 \mathrm{~h}$ followed by TSA treatment for 8 or $24 \mathrm{~h}$. To ascertain the biological activity of $p 53$ WT on CNE2 cells, cotransfection of $p 53 \mathrm{WT}$ and p53 luciferase reporter was conducted and the respective luciferase activities were measured. As shown in Fig. 3A, the overexpression of $p 53$ WT dramatically stimulated the p53 reporter activities (108-fold induction vs pCMV). At the protein level, the overexpression of $p 53 \mathrm{WT}$ increased the levels of p53 acetylation at Lys382 (Fig. 3B). Although p53 overexpression had no perceptible effect on STC1 mRNA expression, it could enhance STC1 mRNA expression in TSA cotreatment by $2 \cdot 5$-fold at $8 \mathrm{~h}$ (vs pCMV+TSA; Fig. 3C).

According to the core DNA-binding sequence (-CATG-) of p53, ten putative p53 binding sites $(-2612 /-2615$, $-2575 /-2578, \quad-2530 /-2533, \quad-1201 /-1204$, $-1133 /-1136,-892 /-895,-851 /-854,-505 /-508$, $-497 /-500$, and $-106 /-109)$ were mapped on $\sim 3 \mathrm{~kb}$
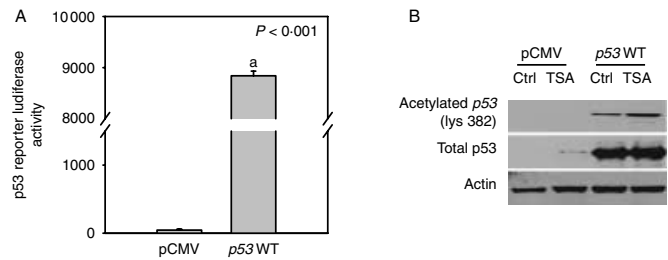

C

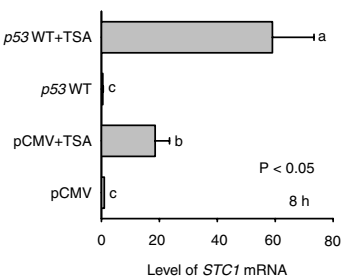

$\mathrm{E}$
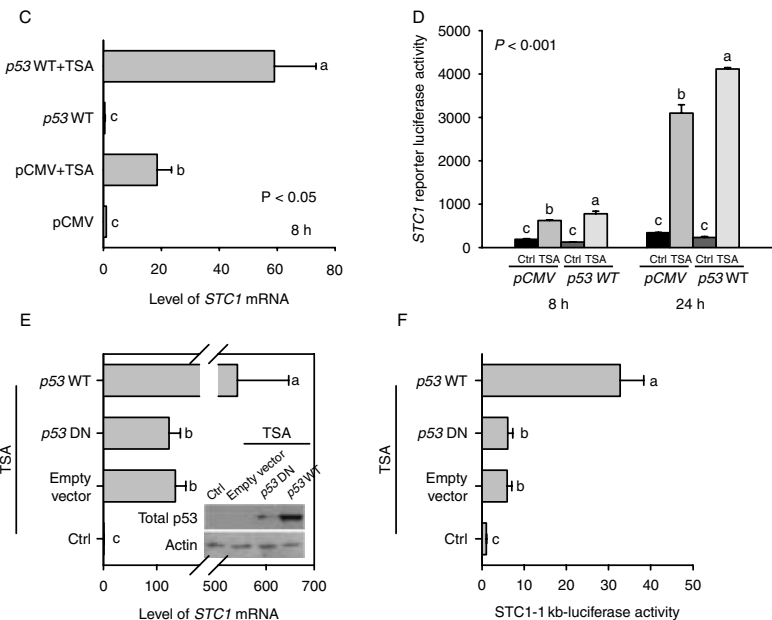

Figure 3 Effects of p53 overexpression on STC1 gene regulation. (A) CNE2 cells were cotransfected with pCMV encoding p53 WT and p53 luciferase reporter, and the luciferase activities were measured at $8 \mathrm{~h}$. (B) The p53 WT-transfected cells were treated with $200 \mathrm{ng} / \mathrm{ml} \mathrm{TSA}$ for $8 \mathrm{~h}$, protein lysates were harvested, and protein expressions of acetylated p53 (lys382), total p53, and actin were determined using western blot. (C) Total RNAs after $8 \mathrm{~h}$ of TSA treatment in the transfected cells were harvested and STC1 mRNA expression was examined by real-time PCR $(P<0.05)$. (D) After cotransfection of $p C M V$ plasmids and STC1 reporter encoding $1 \mathrm{k}$ STC1 promoter regions for $24 \mathrm{~h}$, the cells were treated with TSA and harvested at 8 and $24 \mathrm{~h}$ for the measurement of luciferase activities $(P<0.001)$. (E) After transfection of pCMV encoding p53 WT, p53 DN, or the empty vector, STC1 mRNA expression was examined at $24 \mathrm{~h}$. The protein expression levels of total p53 and actin are shown (right). (F) CNE2 cells were cotransfected with the p53 luciferase reporter and the pCMV encoding p53 WT, p53 DN or the empty vector alone, the respective luciferase activities were measured at $24 \mathrm{~h}$. Bars with the same letter are not significantly different according to the results of one-way ANOVA followed by Duncan's multiple range tests. 
STC1 promoter region. To test the effect of the exogenous $p 53$ WT overexpression on STC1 promoterdriven activities, STC1 luciferase reporters encoding different promoter regions (STC 1-4k) were constructed for the assays (Supplementary Figure 3A, see section on supplementary data given at the end of this article). Surprisingly, the overexpression of $p 53 \mathrm{WT}$ did not elicit noticeable effect on STC1 promoter-driven luciferase activities among various STC1 promoter constructs (Supplementary Figure 3B, see section on supplementary data given at the end of this article). Owing to the similar responses obtained from various STC1 promoter regions, the construct encoding the proximal promoter region STC1 1k was used for the subsequent treatments. In STC1 promoter analysis, the respective stimulatory or synergistic effects of TSA or TSA $+p 53 \mathrm{WT}$ treatments on STC1 promoter-driven luciferase activity were observed at 8 and $24 \mathrm{~h}(1 \cdot 2-$ and $1 \cdot 3$-fold induction in $p 53 \mathrm{WT}+\mathrm{TSA}$ vs their pCMV+ TSA at 8 and $24 \mathrm{~h}$ respectively) (Fig. 3D). To reveal whether the synergistic effects were due to the overexpression of the functional p53, the $p 53$ mutant DN was also used to test its effects on TSA-elicited STC1 mRNA expression (Fig. 3E) and STC1-driven luciferase activity (Fig. 3F). Consistently, no noticeable effects were observed in TSA $+p 53 \mathrm{DN}$-treated cells compared with TSA alone or TSA+empty vector treatments.

Our data suggested that p53 could significantly induce TSA-mediated STC1 gene expression; however, a ChIP assay using p53 antibody did not show an enrichment of STC1 promoter region (data not shown). The data suggested that p53-mediated activation of STC1 gene expression might be attributed by other or indirect pathways. In the investigation of the signaling pathways involved in p53-mediated STC1 expression, western blot analysis revealed significant increases in the levels of acetylated-NF- $\kappa \mathrm{B}$ and

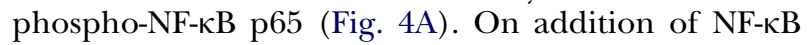
inhibitor PTL to TSA + Dox-cotreated cells, the level of STC1 mRNA expression was significantly reduced (Fig. 4B). Moreover, TSA+Dox cotreatment significantly increased the levels of acetylated histone H3 compared with the TSA alone treatment (Fig. 4C). Acquiring ChIP assay using acetylated histone H3 antibody, STC1 DNA was also markedly enriched after TSA+Dox cotreatment (Fig. 4D).

\section{The pro-apoptotic role of STC1 in Dox-induced apoptosis}

We attempted to investigate whether STC1 was able to modulate Dox-induced apoptosis. CNE2 cells were transiently transfected with V5-tagged STC1 pLenti6.3/ V5-DEST with the minimum transfection efficiency of $70 \%$. By western blotting, V5-tagged STC1 expression was remarkably induced in plenti6.3-STC1-transfected
A

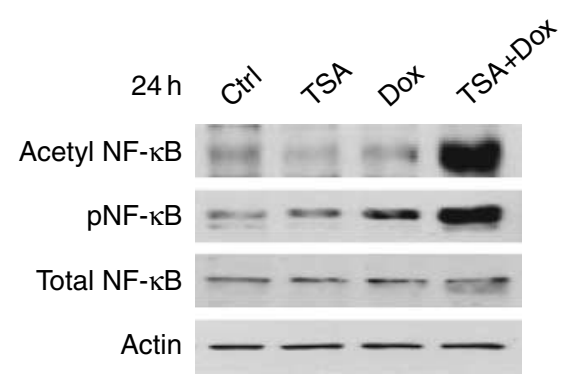

B

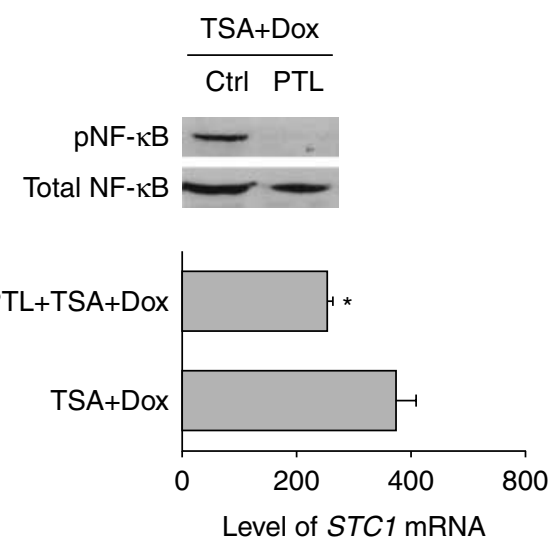

C

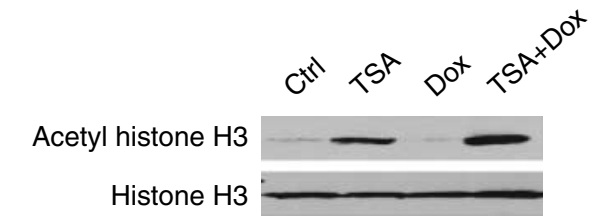

D

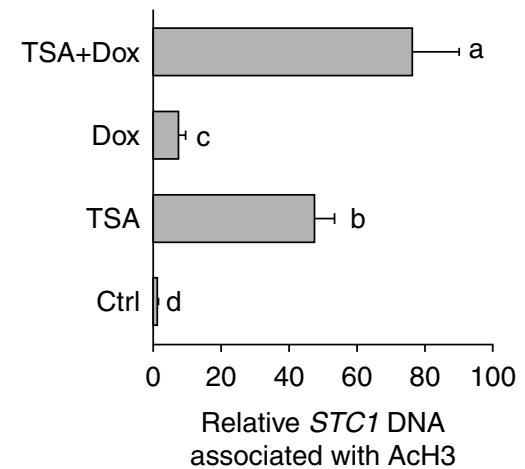

Figure 4 Effects of TSA + Dox cotreatment on NF- $\mathrm{KB}$ signaling and acetylation of histone H3. (A) CNE2 cells were treated with TSA and/or Dox for $24 \mathrm{~h}$ and protein lysates were harvested for western blotting using antibodies for acetylated NF- $\mathrm{BB}$, phospho-NF- $\mathrm{BB}$ p65, total NF-kB, and actin. (B) CNE2 cells were pretreated with parthenolide (PTL) for $1 \mathrm{~h}$ before TSA + Dox cotreatment, then protein lysate and total RNA were prepared for western blotting and real-time PCR respectively $(P<0.05)$. (C) An increase in the protein expression levels of acetyl histone $\mathrm{H} 3$ was detected upon TSA and/or Dox treatments, whereas histone $\mathrm{H} 3$ was used as a loading control. (D) ChIP assay illustrated the significant increase in acetyl histone $\mathrm{H} 3(\mathrm{AcH} 3)$ binding on STC1 promoter $(-90$ to +11 bp $)$ in TSA and TSA + Dox-cotreated CNE2 cells $(P<0.05)$. 
cells (vs plenti6.3) at $24 \mathrm{~h}$ posttransfection (Fig. 5A). With the overexpression of exogenous STC1, the percentage of apoptotic cells was noticeably enhanced in Dox-cotreated cells (1-4-fold vs plenti6.3+Dox; Fig. 5B).

\section{Discussion}

Considerable studies have demonstrated the involvement of STC1 in human carcinogenesis. Current evidence illustrates the differential expression patterns of STC1 in paired tumor and normal tissues (Liu et al. 2010, Tamura et al. 2011). A role of STC1 in the tumor microenvironment has also been suggested (Yeung et al. 2012). This presumption is strengthened by the involvement of STC1 in local inflammation (SheikhHamad 2010) as well as the identification of STC1 as a hypoxia and angiogenic responsive gene (Yeung et al. 2005, Law et al. 2010, Jauhiainen et al. 2011, Roch \& Sherwood 2011). To date, biological roles of STC1 in carcinogenesis have been suggested, including cell motility, invasion, and apoptosis (Lai et al. 2007, Law et al. 2008, Liu et al. 2010). However, the mechanistic role of STC1 in the cell death pathway is still not clear as both pro-apoptotic and antiapoptotic roles have been demonstrated. Moreover, the regulatory function of p53 in STC1 gene transcription is still not clear. In this study, we provided new evidence to relate the transcriptional role of p53 in STC1 gene transactivation. A crosstalk mechanism among p53, NF- $\kappa \mathrm{B}$, and histone $\mathrm{H} 3$ acetylation in the regulation of $S T C 1$ gene expression was suggested. Furthermore, the overexpression of exogenous STC1 was found to sensitize apoptosis induced by Dox treatment, supporting the proapoptotic role of the protein.

HDAC inhibitors, an important class of anticancer agents, have been developed to promote acetylation on chromatin-associated (histone) and non-chromatinassociated proteins (i.e. NF- $\mathrm{B}$ and p53). Generally, HDAC inhibitor treatment leads to multiple cellular consequences such as ROS generation, cell cycle arrest, apoptosis, and inhibition of angiogenesis (Bolden $\mathrm{et} \mathrm{al}$. 2006). Other studies have demonstrated that TSA could promote apoptosis induced by Dox treatment (Karagiannis et al. 2004, Rho et al. 2005) via the activation of p53-signaling pathway (Magnelli et al. 1995, Brantley-Finley et al. 2003, Tang et al. 2004, Wang et al. 2004). Human STC1 has been suggested to be a putative p53 downstream target and is involved in apoptosis (Wu et al. 2006, Lai et al. 2007, Law et al. 2008, Nguyen et al. 2009). In this study, the data of western blotting, real-time PCR, and p53-luciferase reporter assays showed that p53 was activated in the Dox-treated cells. TSA and Dox cotreatment synergistically enhanced the induction of apoptosis and STC1
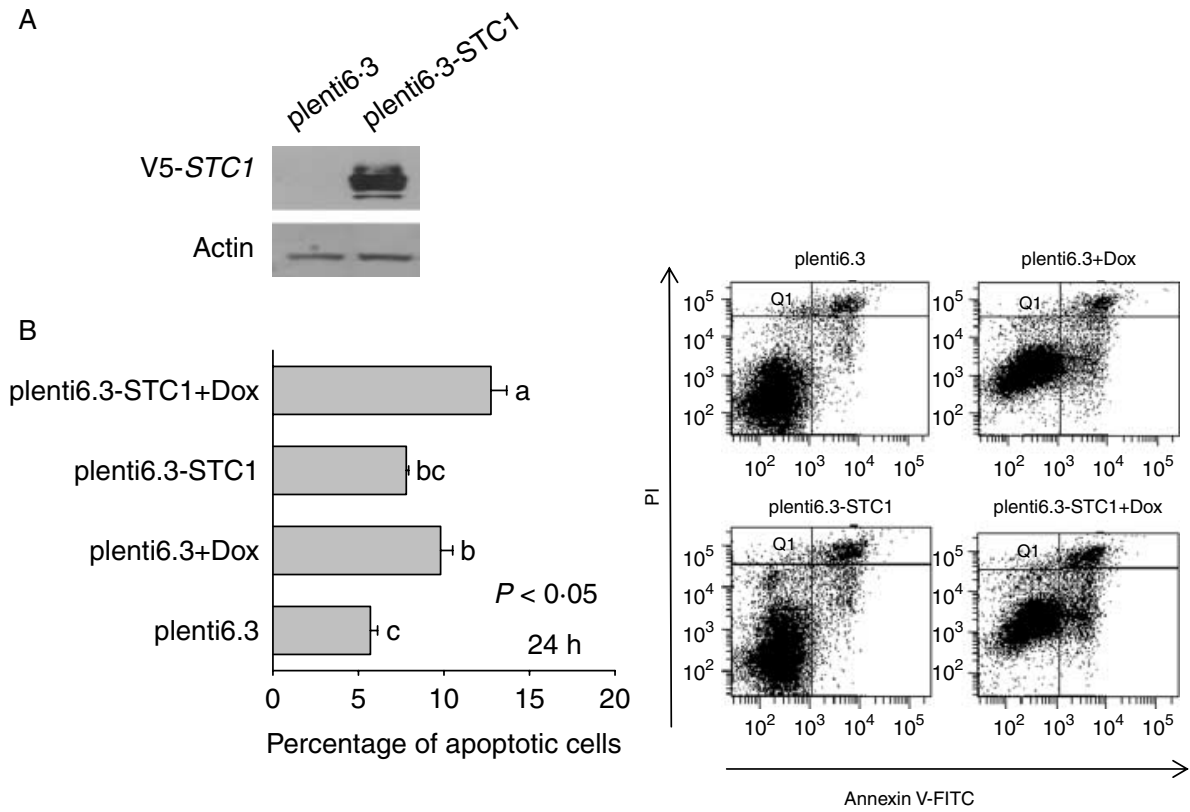

Figure 5 The effects of STC1 overexpression on Dox-induced apoptosis. (A) Protein lysates of STC1 overexpressed cells were collected and probed with V5 antibody. (B) CNE2 cells were overexpressed with exogenous STC1 followed by $24 \mathrm{~h}$ Dox treatment. Percentages of apoptotic cells (Annexin $\mathrm{V}-\mathrm{FITC}^{+\mathrm{ve}} / \mathrm{PI}^{-\mathrm{ve}}$, the lower right quadrant in the plot) were counted using flow cytometric analysis $(P<0 \cdot 05)$. Bars with the same letter are not significantly different according to the results of one-way ANOVA followed by Duncan's multiple range tests. 
expression. To decipher the underlying mechanism of the synergistic effects, we attempted to overexpress the exogenous $p 53 \mathrm{WT}$ in TSA-treated cells. A similar observation of the synergistic effect on STC1 expression was observed. Upon TSA treatment, the levels of p53 acetylation (Lys382) were increased, which is crucial for its stabilization against ubiquitylation and its mediated function (Rodriguez et al. 2000, Ito et al. 2001, Luo et al. 2004). Indeed, in a breast cancer model, acetylated p53 (Lys373/382) was recruited on gene promoter regions such as BANP after Dox treatment, leading to the activation of gene transcription (Singh et al. 2007). However, in a STC1 promoter deletion assay, p53 overexpression showed no noticeable effects on STC1 promoter-driven luciferase activities. ChIP analysis also revealed no direct binding of p53 on the STC1 promoter (data on shown). The data suggest that p53 was not involved in the direct transactivation of STC1 gene expression. However, it has been reported that one of the key proteins that mediated p53-induced apoptosis is NF-KB (Ryan et al. 2000), which is also known to regulate a $S T C 1$ gene transcription (Law et al. 2008). In addition, p53-dependent histone acetylation has been reported (Kaeser \& Iggo 2004). With the benefit of hindsight, our western blot data illustrated that Dox and TSA cotreatment significantly elevated the cellular levels of phospho-NF- $\mathrm{B}$ and acetylated histone H3. The demonstration of the inhibitory effects of NF- $\kappa \mathrm{B}$ inhibitor on STC1 expression in TSA+Doxcotreated cells denoted the dependence of NF- $\kappa$ Bsignaling on STC1 gene expression. Moreover, the ChIP assay illustrated that the cotreatment caused a significant increase in acetylated histone $\mathrm{H} 3$ binding on STC1 proximal promoter. The p53-mediated increase in the levels of phospho-NF- $\mathrm{B}$ was reported to be related to p53-stimulated pp90 $0^{\text {rsk }}$ activity (Ryan et al. 2000),

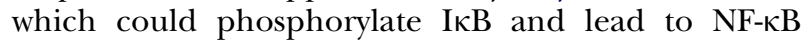
activation. The increase in histone acetylation may be associated with the progressive recruitment of chromatin-modifying enzymes on p53, promoting the activity of p53-dependent histone acetylation (Agalioti et al. 2002, Lee et al. 2002, Espinosa et al. 2003). Whatever the explanation, the TSA and Dox/p53 WT cotreatment significantly induced STC1 gene expression and cellular apoptosis. The pro-apoptotic role of STC1 was supported by the STC1 overexpression experiments, in which STC1 sensitized the apoptotic process in Doxtreated cells. Although our data support the proapoptotic function of STC1, other studies have demonstrated the anti-apoptotic activity of the protein (Zhang et al. 2000, Block et al. 2009). This inconsistency may not be contradictory as the transcriptional factor, $\mathrm{NF}-\kappa \mathrm{B}$, is also known to be able to protect or contribute to apoptosis (Foo \& Nolan 1999, Fan et al. 2008). Therefore, STC1 may not be a key regulator for or against apoptosis; the particular role of STC1 is probably dependent on the extent of cellular stress imposed to the cells (Yeung et al. 2012).

Collectively, our study demonstrated that the cotreatment of TSA and Dox in CNE2 cells could remarkably induce STC1 activation. Although the evidence of p53mediated direct transactivation of STC1 promoter regions was not identified, TSA+Dox-induced STC1 was found to be mediated via p53 to increase the levels of histone $\mathrm{H} 3$ acetylation and NF- $\mathrm{B}$ phosphorylation.

\section{Supplementary data}

This is linked to the online version of the paper at http://dx.doi.org/ 10.10.1530/JME-11-0159.

\section{Declaration of interest}

The authors declare that there is no conflict of interest that could be perceived as prejudicing the impartiality of the research reported.

\section{Funding}

This work was supported by the Faculty Research Grant (FRG2/09/10/053), Hong Kong Baptist University (C K C W).

\section{References}

Agalioti T, Chen G \& Thanos D 2002 Deciphering the transcriptional histone acetylation code for a human gene. Cell 111 381-392. (doi:10.1016/S0092-8674(02)01077-2)

Allen M \& Louise Jones J 2011 Jekyll and Hyde: the role of the microenvironment on the progression of cancer. Journal of Pathology 223 162-176. (doi:10.1002/path.2803)

Block GJ, Ohkouchi S, Fung F, Frenkel J, Gregory C, Pochampally R, DiMattia G, Sullivan DE \& Prockop DJ 2009 Multipotent stromal cells are activated to reduce apoptosis in part by upregulation and secretion of stanniocalcin-1. Stem Cells 27 670-681. (doi:10.1002/ stem.20080742)

Bolden JE, Peart MJ \& Johnstone RW 2006 Anticancer activities of histone deacetylase inhibitors. Nature Reviews. Drug Discovery 5 769-784. (doi:10.1038/nrd2133)

Brantley-Finley C, Lyle CS, Du L, Goodwin ME, Hall T, Szwedo D, Kaushal GP \& Chambers TC 2003 The JNK, ERK and p53 pathways play distinct roles in apoptosis mediated by the antitumor agents vinblastine, doxorubicin, and etoposide. Biochemical Pharmacology 66 459-469. (doi:10.1016/S0006-2952(03) 00255-7)

Chang AC, Janosi J, Hulsbeek M, de Jong D, Jeffrey KJ, Noble JR \& Reddel RR 1995 A novel human cDNA highly homologous to the fish hormone stanniocalcin. Molecular and Cellular Endocrinology 112 241-247. (doi:10.1016/0303-7207(95)03601-3)

Chang AC, Dunham MA, Jeffrey KJ \& Reddel RR 1996 Molecular cloning and characterization of mouse stanniocalcin cDNA. Molecular and Cellular Endocrinology 124 185-187. (doi:10.1016/ S0303-7207(96) 03929-9)

Chang AC, Jeffrey KJ, Tokutake Y, Shimamoto A, Neumann AA, Dunham MA, Cha J, Sugawara M, Furuichi Y \& Reddel RR 1998 Human stanniocalcin (STC): genomic structure, chromosomal localization, and the presence of CAG trinucleotide repeats. Genomics 47 393-398. (doi:10.1006/geno.1997.5120) 
Chang AC, Jellinek DA \& Reddel RR 2003 Mammalian stanniocalcins and cancer. Endocrine-Related Cancer 10 359-373. (doi:10.1677/erc.0. 0100359)

Chughtai SA, Crundwell MC, Cruickshank NR, Affie E, Armstrong S, Knowles MA, Takle LA, Kuo M, Khan N, Phillips SM et al. 1999 Two novel regions of interstitial deletion on chromosome $8 \mathrm{p}$ in colorectal cancer. Oncogene 18 657-665. (doi:10.1038/sj.onc. 1202340)

De Niu P, Radman DP, Jaworski EM, Deol H, Gentz R, Su J, Olsen HS \& Wagner GF 2000 Development of a human stanniocalcin radioimmunoassay: serum and tissue hormone levels and pharmaco kinetics in the rat. Molecular and Cellular Endocrinology 162 131-144. (doi:10.1016/S0303-7207(00)00199-4)

Ellard JP, McCudden CR, Tanega C, James KA, Ratkovic S, Staples JF \& Wagner GF 2007 The respiratory effects of stanniocalcin-1 (STC-1) on intact mitochondria and cells: STC-1 uncouples oxidative phosphorylation and its actions are modulated by nucleotide triphosphates. Molecular and Cellular Endocrinology 264 90-101. (doi:10.1016/j.mce.2006.10.008)

Espinosa JM, Verdun RE \& Emerson BM 2003 p53 functions through stress- and promoter-specific recruitment of transcription initiation components before and after DNA damage. Molecular Cell 12 1015-1027. (doi:10.1016/S1097-2765(03)00359-9)

Fan Y, Dutta J, Gupta N, Fan G \& Gelinas C 2008 Regulation of programmed cell death by NF-kappaB and its role in tumorigenesis and therapy. Advances in Experimental Medicine and Biology 615 223-250. (doi:10.1007/978-1-4020-6554-5_11)

Foo SY \& Nolan GP 1999 NF-kappaB to the rescue: RELs, apoptosis and cellular transformation. Trends in Genetics 15 229-235. (doi:10.1016/S0168-9525(99)01719-9)

Gerritsen ME \& Wagner GF 2005 Stanniocalcin: no longer just a fish tale. Vitamins and Hormones 70 105-135. (doi:10.1016/S00836729(05)70004-2)

Gupta SC, Kim JH, Prasad S \& Aggarwal BB 2010 Regulation of survival, proliferation, invasion, angiogenesis, and metastasis of tumor cells through modulation of inflammatory pathways by nutraceuticals. Cancer Metastasis Reviews 29 405-434. (doi:10.1007/ s10555-010-9235-2)

Ito A, Lai CH, Zhao X, Saito S, Hamilton MH, Appella E \& Yao TP 2001 p300/CBP-mediated p53 acetylation is commonly induced by p53-activating agents and inhibited by MDM2. EMBO Journal 20 1331-1340. (doi:10.1093/emboj/20.6.1331)

Jauhiainen S, Hakkinen SK, Toivanen PI, Heinonen SE, Jyrkkanen HK, Kansanen E, Leinonen H, Levonen AL \& Yla-Herttuala S 2011 Vascular endothelial growth factor (VEGF)-D stimulates VEGF-A, stanniocalcin-1, and neuropilin-2 and has potent angiogenic effects. Arteriosclerosis, Thrombosis, and Vascular Biology 31 1617-1624. (doi:10.1161/ATVBAHA.111.225961)

Kaeser MD \& Iggo RD 2004 Promoter-specific p53-dependent histone acetylation following DNA damage. Oncogene 23 4007-4013. (doi:10.1038/sj.onc.1207536)

Karagiannis TC, Smith AJ \& El' Osta A 2004 Radio- and chemosensitization of human erythroleukemic K562 cells by the histone deacetylase inhibitor trichostatin A. Hellenic Journal of Nuclear Medicine 7 184-191.

Khanal RC \& Nemere I 2008 Endocrine regulation of calcium transport in epithelia. Clinical and Experimental Pharmacology E̋ Physiology 35 1277-1287. (doi:10.1111/j.1440-1681.2008. 05053.x)

Lai KP, Law AY, Yeung HY, Lee LS, Wagner GF \& Wong CK 2007 Induction of stanniocalcin-1 expression in apoptotic human nasopharyngeal cancer cells by p53. Biochemical and Biophysical Research Communications 356 968-975. (doi:10.1016/j.bbrc.2007. 03.074)

Law AY, Lai KP, Lui WC, Wan HT \& Wong CK 2008 Histone deacetylase inhibitor-induced cellular apoptosis involves stanniocalcin-1 activation. Experimental Cell Research 314 2975-2984. (doi:10.1016/ j.yexcr.2008.07.002)
Law AY, Ching LY, Lai KP \& Wong CK 2010 Identification and characterization of the hypoxia-responsive element in human stanniocalcin-1 gene. Molecular and Cellular Endocrinology 314 118-127. (doi:10.1016/j.mce.2009.07.007)

Lee D, Kim JW, Seo T, Hwang SG, Choi EJ \& Choe J 2002 SWI/SNF complex interacts with tumor suppressor p53 and is necessary for the activation of p53-mediated transcription. Journal of Biological Chemistry 277 22330-22337. (doi:10.1074/jbc.M111987200)

Liu G, Yang G, Chang B, Mercado-Uribe I, Huang M, Zheng J, Bast RC, Lin SH \& Liu J 2010 Stanniocalcin 1 and ovarian tumorigenesis. Journal of the National Cancer Institute 102 812-827. (doi:10.1093/ jnci/djq127)

Lopez-Novoa JM \& Nieto MA 2009 Inflammation EMT: an alliance towards organ fibrosis and cancer progression. EMBO Molecular Medicine 1 303-314. (doi:10.1002/emmm.200900043)

Lu M, Wagner GF \& Renfro JL 1994 Stanniocalcin stimulates phosphate reabsorption by flounder renal proximal tubule in primary culture. American Journal of Physiology 267 R1356-R1362.

Luo J, Li M, Tang Y, Laszkowska M, Roeder RG \& Gu W 2004 Acetylation of p53 augments its site-specific DNA binding both in vitro and in vivo. PNAS 101 2259-2264. (doi:10.1073/pnas. 0308762101)

Macartney-Coxson DP, Hood KA, Shi HJ, Ward T, Wiles A, O'Connor R, Hall DA, Lea RA, Royds JA, Stubbs RS et al. 2008 Metastatic susceptibility locus, an $8 \mathrm{p}$ hot-spot for tumour progression disrupted in colorectal liver metastases: 13 candidate genes examined at the DNA, mRNA and protein level. BMC Cancer 8 187. (doi:10.1186/14712407-8-187)

Madsen KL, Tavernini MM, Yachimec C, Mendrick DL, Alfonso PJ, Buergin M, Olsen HS, Antonaccio MJ, Thomson AB \& Fedorak RN 1998 Stanniocalcin: a novel protein regulating calcium and phosphate transport across mammalian intestine. American Journal of Physiology 274 G96-102.

Magnelli L, Cinelli M \& Chiarugi V 1995 Phorbol esters attenuate the expression of p53 in cells treated with doxorubicin and protect TS-P53/K562 from apoptosis. Biochemical and Biophysical Research Communications 215 641-645. (doi:10.1006/bbrc.1995.2512)

Nguyen A, Chang AC \& Reddel RR 2009 Stanniocalcin-1 acts in a negative feedback loop in the prosurvival ERK1/2 signaling pathway during oxidative stress. Oncogene 28 1982-1992. (doi:10.1038/onc.2009.65)

Olsen HS, Cepeda MA, Zhang QQ, Rosen CA \& Vozzolo BL 1996 Human stanniocalcin: a possible hormonal regulator of mineral metabolism. PNAS 93 1792-1796. (doi:10.1073/pnas.93.5.1792)

Pani G, Galeotti T \& Chiarugi P 2010 Metastasis: cancer cell's escape from oxidative stress. Cancer Metastasis Reviews 29 351-378. (doi:10.1007/s10555-010-9225-4)

Parniewski P \& Staczek P 2002 Molecular mechanisms of TRS instability. Advances in Experimental Medicine and Biology 516 1-25.

Re RN \& Cook JL 2010 The mitochondrial component of intracrine action. American Journal of Physiology. Heart and Circulatory Physiology 299 H577-H583. (doi:10.1152/ajpheart.00421.2010)

Rho JH, Kang DY, Park KJ, Choi HJ, Lee HS, Yee SB \& Yoo YH 2005 Doxorubicin induces apoptosis with profile of large-scale DNA fragmentation and without DNA ladder in anaplastic thyroid carcinoma cells via histone hyperacetylation. International Journal of Oncology 27 465-471.

Roch GJ \& Sherwood NM 2011 Stanniocalcin has deep evolutionary roots in eukaryotes. Genome Biology and Evolution 3 284-294. (doi:10.1093/gbe/evr020)

Rodriguez MS, Desterro JM, Lain S, Lane DP \& Hay RT 2000 Multiple C-terminal lysine residues target p53 for ubiquitin-proteasomemediated degradation. Molecular and Cellular Biology 20 8458-8467. (doi:10.1128/MCB.20.22.8458-8467.2000)

Ryan KM, Ernst MK, Rice NR \& Vousden KH 2000 Role of NF-kappaB in p53-mediated programmed cell death. Nature 404 892-897. (doi:10.1038/35009130) 
Schreiber RD, Old LJ \& Smyth MJ 2011 Cancer immunoediting: integrating immunity's roles in cancer suppression and promotion. Science 331 1565-1570. (doi:10.1126/science.1203486)

Sheikh-Hamad D 2010 Mammalian stanniocalcin-1 activates mitochondrial antioxidant pathways: new paradigms for regulation of macrophages and endothelium. American Journal of Physiology. Renal Physiology 298 F248-F254. (doi:10.1152/ajprenal. 00260.2009)

Shibata D 2011 Mutation and epigenetic molecular clocks in cancer. Carcinogenesis 32 123-128. (doi:10.1093/carcin/bgq239)

Singh K, Mogare D, Giridharagopalan RO, Gogiraju R, Pande G \& Chattopadhyay S 2007 p53 target gene SMAR1 is dysregulated in breast cancer: its role in cancer cell migration and invasion. PLoS ONE 2 e660. (doi:10.1371/journal.pone.0000660)

Suzuki Y, Landowski CP \& Hediger MA 2008 Mechanisms and regulation of epithelial $\mathrm{Ca}^{2+}$ absorption in health and disease. Annual Review of Physiology 70 257-271. (doi:10.1146/annurev. physiol.69.031905.161003)

Tamura S, Oshima T, Yoshihara K, Kanazawa A, Yamada T, Inagaki D, Sato T, Yamamoto N, Shiozawa M, Morinaga S et al. 2011 Clinical significance of STC1 gene expression in patients with colorectal cancer. Anticancer Research 31 325-329.

Tang HJ, Qian D, Sondak VK, Stachura S \& Lin J 2004 A modified p53 enhances apoptosis in sarcoma cell lines mediated by doxorubicin. British Journal of Cancer 90 1285-1292. (doi:10.1038/sj.bjc.6601653)

Varghese R, Wong CK, Deol H, Wagner GF \& DiMattia GE 1998 Comparative analysis of mammalian stanniocalcin genes. Endocrinology 139 4714-4725. (doi:10.1210/en.139.11.4714)

Wagner GF, Fargher RC, Milliken C, McKeown BA \& Copp DH 1993 The gill calcium transport cycle in rainbow trout is correlated with plasma levels of bioactive, not immunoreactive, stanniocalcin. Molecular and Cellular Endocrinology 93 185-191. (doi:10.1016/03037207(93)90122-Z)
Wagner GF, Vozzolo BL, Jaworski E, Haddad M, Kline RL, Olsen HS, Rosen CA, Davidson MB \& Renfro JL 1997 Human stanniocalcin inhibits renal phosphate excretion in the rat. Journal of Bone and Mineral Research 12 165-171. (doi:10.1359/jbmr.1997.12.2.165)

Wagner GF, Jaworski EM \& Haddad M 1998 Stanniocalcin in the seawater salmon: structure, function, and regulation. American Journal of Physiology 274 R1177-R1185.

Wang S, Konorev EA, Kotamraju S, Joseph J, Kalivendi S \& Kalyanaraman B 2004 Doxorubicin induces apoptosis in normal and tumor cells via distinctly different mechanisms. intermediacy of $\mathrm{H}(2) \mathrm{O}(2)$ - and p53-dependent pathways. Journal of Biological Chemistry 279 25535-25543. (doi:10.1074/jbc.M400944200)

Wu S, Yoshiko Y \& De Luca F 2006 Stanniocalcin 1 acts as a paracrine regulator of growth plate chondrogenesis. Journal of Biological Chemistry 281 5120-5127. (doi:10.1074/jbc.M506667200)

Yeung HY, Lai KP, Chan HY, Mak NK, Wagner GF \& Wong CK 2005 Hypoxia-inducible factor-1-mediated activation of stanniocalcin-1 in human cancer cells. Endocrinology 146 4951-4960. (doi:10.1210/ en.2005-0365)

Yeung BH, Law AY \& Wong CK 2012 Evolution and roles of stanniocalcin. Molecular and Cellular Endocrinology 349 272-280. (doi:10.1016/j.mce.2011.11.007)

Yoshiko Y \& Aubin JE 2004 Stanniocalcin 1 as a pleiotropic factor in mammals. Peptides 25 1663-1669. (doi:10.1016/j.peptides.2004.04. 015)

Zhang K, Lindsberg PJ, Tatlisumak T, Kaste M, Olsen HS \& Andersson LC 2000 Stanniocalcin: a molecular guard of neurons during cerebral ischemia. PNAS 97 3637-3642. (doi:10.1073/pnas. 070045897)

Received in final form 26 February 2012

Accepted 3 April 2012

Made available online as an Accepted Preprint 3 April 2012 